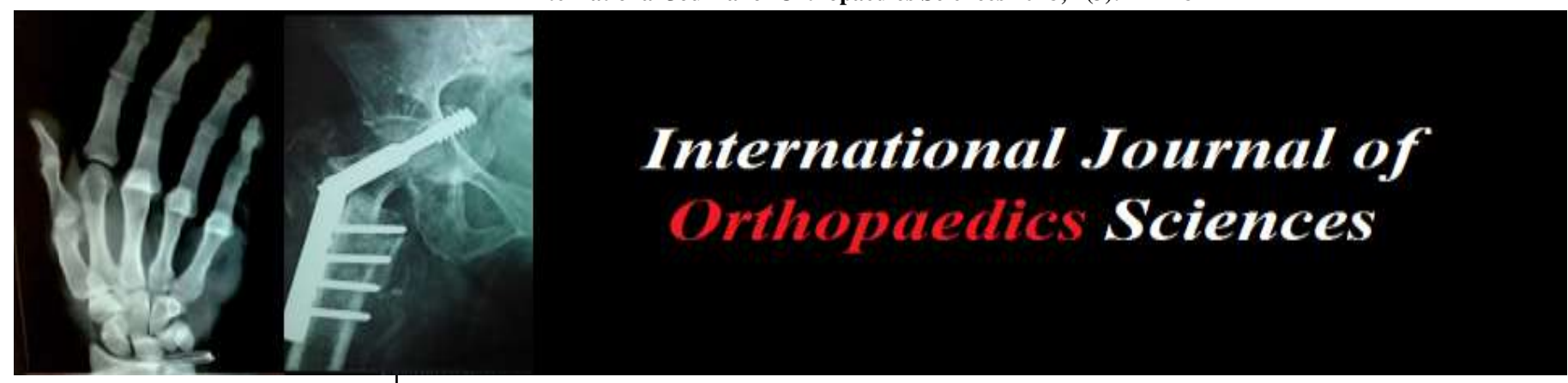

ISSN: $2395-1958$

IJOS 2018; 4(3): 277-281

(C) 2018 IJOS

www.orthopaper.com

Received: 19-05-2018

Accepted: 20-06-2018

Dr. Wachche Gurunath S MS. Orthopedics, Wachche Hospital, Jule, Solapur,

Maharashtra, India

\section{Our experience of titanium elastic nailing for paediatric diaphyseal femoral fractures in a series of 25 cases}

\section{Dr. Wachche Gurunath S}

DOI: $\underline{\text { https://doi.org/10.22271/ortho.2018.v4.i3e.49 }}$

\section{Abstract}

Pediatric femoral diaphyseal fractures are still managed conservatively by many surgeons, due to rapid healing and remodelling of the deformities. They are often associated with various complications. The fractures of shaft femur ain children are treated with various types of traction for about three weeks by cast. There are two major drawbacks, one is prolonged bed rest which separates child from his routine activity which in turn adds to more cost of hospitalisation. But with the advent of Elastic stable Intramedullary Nailing [ESIN], such fractures can be treated with surgical treatment to minimise all the disadvantages. The closed surgical treatment of these fractures allows early weight bearing and walking which facilitates early bridging callus and rapid restoration of bone continuity.

Keywords: Pediatric femur fractures, titanium elastic nails

\section{Introduction}

Femoral shaft fractures are among the most common major pediatric injuries, treated by orthopaedic surgeons. Various methods of treatment available for femoral shaft fractures in children. In the last $20 \mathrm{yrs}$ there has been trend towards the operative treatment for middle aged children between 6-15 years ${ }^{[9]}$. The main aim of femoral shaft fractures fixation is to attain early mobilisation which in turn encourages restoration of the movements. This will hastens psychological recovery for the patient. There are a wide variety of surgical and nonsurgical treatment options available like spica cast, traction followed by casting, external fixation, plate fixation, intramedullary nails and flexible intramedullary nails. In the last few decades operative stabilization of femoral shaft fractures has gained popularity due to problems of non - operative treatment options. All these problems have been addressed by ESIN. This was introduced for femoral shaft fractures by Nancy group in 1979.

ESIN are flexible nails that allow adequate bending and avoid the need to cross the physis during insertion. ESIN requires relatively small incision and easy hardware removal. ESIN technique causes minimal soft-tissue trauma, quick recovery and shorter hospital stay. ESIN are load sharing implants which maintains reduction for few weeks till callus formation with minimal blood loss. The elasticity of nail promotes callus formation by reducing stress. The titanium implants also has excellent biocompatibility. In the last ten years the Enders nails and titanium elastic nails have been used widely. With this our focus of study is mainly on use of ESIN in respect with closed procedure, minimal blood loss, less hospitalisation, safe procedure which allows early return to the homely environment for the children.

\section{Material and \& Methods}

In our study of total 25 patients with 25 femur fractures included between 2015 to 2018 in our Hospital. We studied 25 children with 25 femoral shaft fractures in age group above 6 , treated with ESIN. After the admission of the patient in the hospital, complete survey was done to rule out other injuries. Plain X-ray of femur, both AP and lateral views including both hip and knee joints were taken. Fracture limb was rested in Thomas spint. All routine blood investigations were done. Detailed consent for surgery was taken. One dose of Intravenous antibiotic is given. The mean age of children ranges from 6 to $14 \mathrm{yrs}{ }^{[9]}$. Out of these fractures, 05 were in the proximal third, 15 in the middle third and 5 were in the distal end. In our series the $40 \%$ of the patients were associated with other injuries like abdominal trauma, head injury.
Dr Wachche Gurunath S.

Associate Professor, Orthopedics, Solapur .413004

Email: gurunathan@yahoo.com 
5 patients had head injuries and 5 had abdominal injuries. The compound fractures are excluded from this study. The most common mechanism of injury was that of a pedestrian being involved in a motor vehicle accident. Right sided involvement was seen in 12 cases. Twelve cases were transverse fractures, 7 were minimally comminuted, and 6 were short oblique fractures. The diameter of the nail measured by measuring the femoral diaphyseal internal diameter in both AP and Lateral $\mathrm{x}$-rays and divided by 2 and $0.5 \mathrm{~mm}$ was subtracted from that calculation for the proper diameter of the nail as determined by Kaser and Beaty ${ }^{[4]}$.

\section{Operative Technique}

The patient is placed over a fracture table with traction under anaesthesia. The skin incision is placed $2.5 \mathrm{~cm}$ above the femoral physis by checking under IITV in AP and lateral views. Fracture is reduced under IITV control. Titanium elastic nails were used which were $45 \mathrm{~cm}$ long with diameters of 3.5 or $4 \mathrm{~mm}$ depending on the weight and age of the patient ${ }^{[10]}$. Entry point is taken with small Awl just above the epiphysis in the metaphysic area. The drill was then inclined so that it made an angle of 10 degrees with the distal physis for easy passage of the nail through the dense metaphyseal bone. The nail tip was bent to facilitate placement and allow nail to bounce off the opposite cortex at the time of insertion. The nail is pushed in the medullary canal under IITV till fracture site, then the fracture was reduced by manipulation and traction and the nail is pushed into the proximal fragment one by one. The tip of medial side nail lie at calcar region of the femoral neck and the lateral side nail lie just distal to the trochanteric apophysis. The distal end of the nail was cut so that at least $1 \mathrm{~cm}$ of nail remains outside cortex for easy removal of nail after fracture union. There is possibility of bursa formation if we keep too much of bend for cut end of nail.

Post-operatively patient were followed up initially at monthly interval for six months and then at three months intervals till the completion of one year. In cases of comminuted fractures, the operated limb is immobilised with above knee slab or Thomas splint postoperatively ${ }^{[2]}$. Patient was started on static quadriceps exercises as soon as pain subsided. Mobilisation started after three days with crutches without weight bearing. After three weeks partial weight bearing was started as per the pain tolerance of the patient. All the patients were followed till union clinically and radiologically. The patients were analysed for radiologically for callus formation, nail position, mal-alignment and shortening. During each follow-up patients were documented for range of motion of knee and hip joint, limb length discrepancy, pain and condition of the wound. The results were evaluated using Flynn et al's scoring criteria for ESIN. Nails were removed after 7 to 10 months duration after radiological union.

\section{Results}

A total of 25 children who underwent Elastic stable intramedullary nailing for femoral diaphyseal fractures were evaluated in this study. The mean age group of the patients in our series was 6 to 14 years. Twenty patients were boys [80\%] and five patients were girls [20\%]. The mean surgical time was 50 to 70 minutes. The total hospital stay was 5 to 12 days. All patients could able to do active hip and knee flexion on second postoperative day only. All the patients returned to school early with average period of 8 to 10 weeks. All the fractures healed with average time of 5 to 14 weeks. ${ }^{[10]} \mathrm{We}$ have advised partial weight bearing in all patients at around 4 to 8 weeks time with help crutches. The full weight bearing started at around 7 to 12 weeks of duration once we could see external callus on $\mathrm{x}$-rays. In one case intraoperative perforation of cortex occurred. We noticed entry site inflammatory changes in three cases. In one case reintroduction of nail was done under local anesthesia. We do not have any cases of deep infection, delayed union and, nonunion in our series. We have done all the cases in closed technique except in 2 cases we have to open the fracture site. There was soft tissue interposition in those two cases ${ }^{[2]}$.

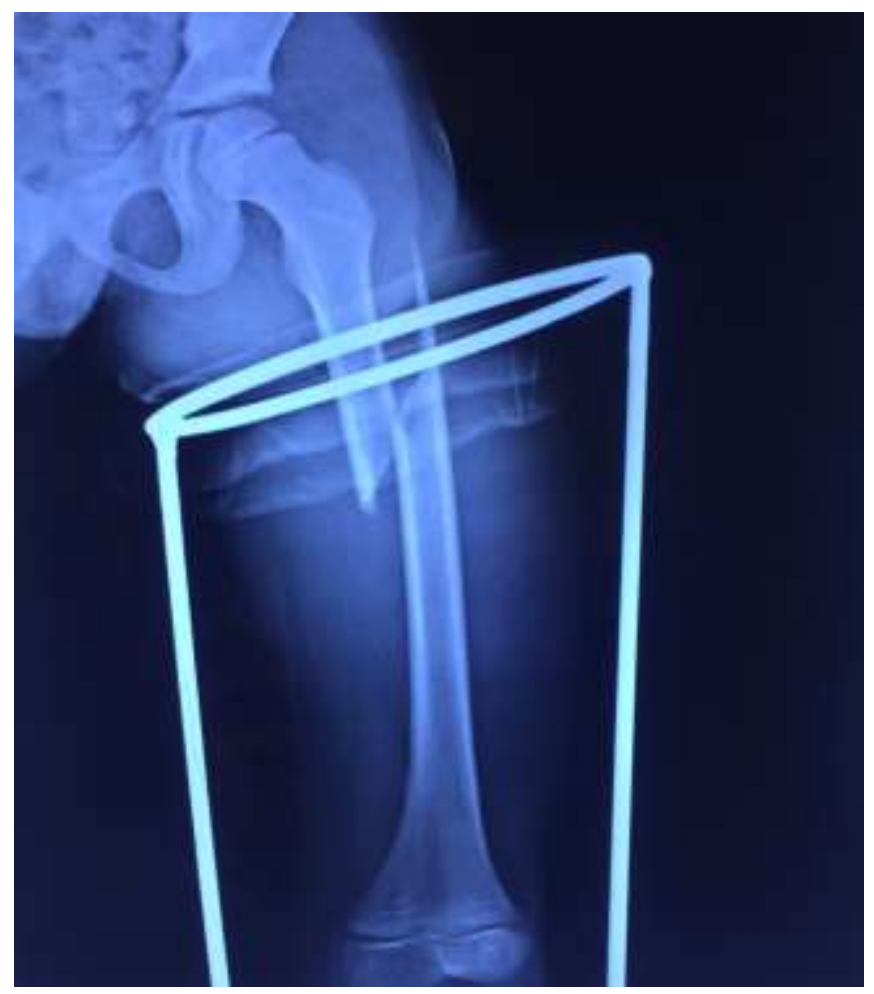

Fig 1: Preoperative radiograph showing long oblique spiral fracture of femoral fracture

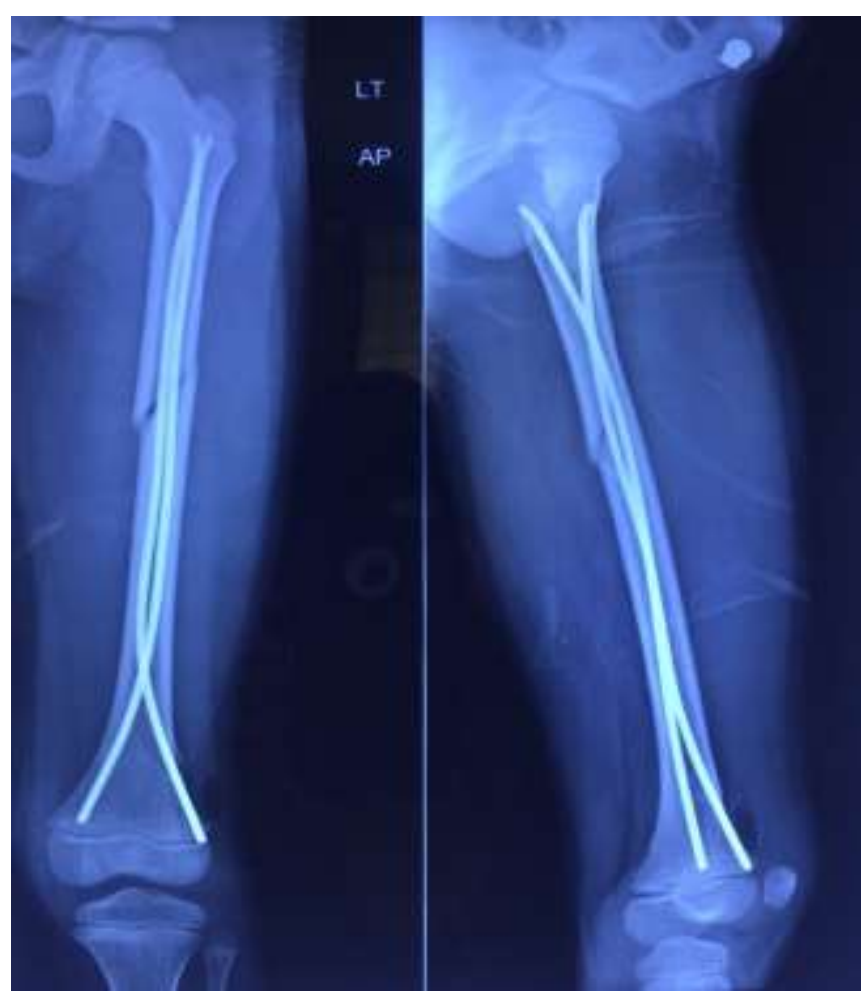

Fig 2: Immediate postoperative anterior posterior and lateral views showing good reduction 


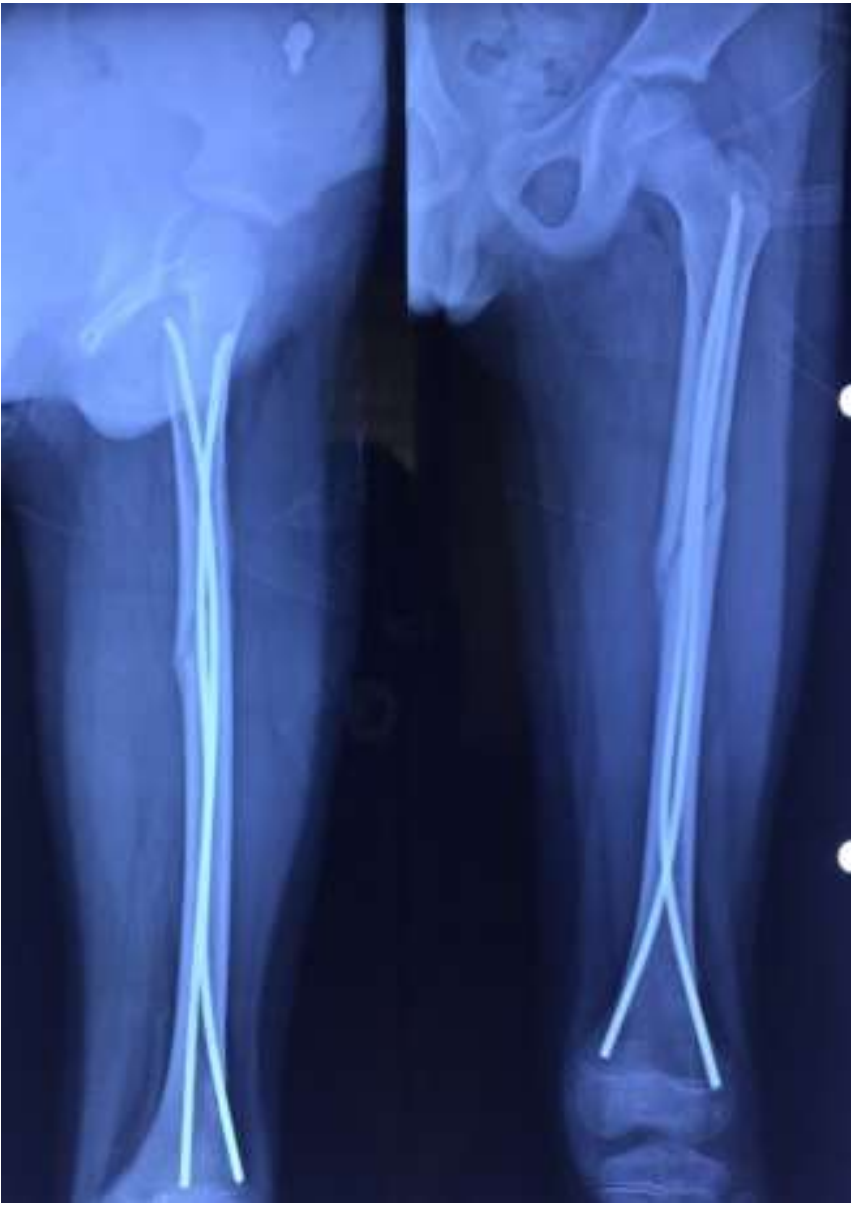

Fig 3: Follow up x-ray after six weeks showing good alignment and union signs

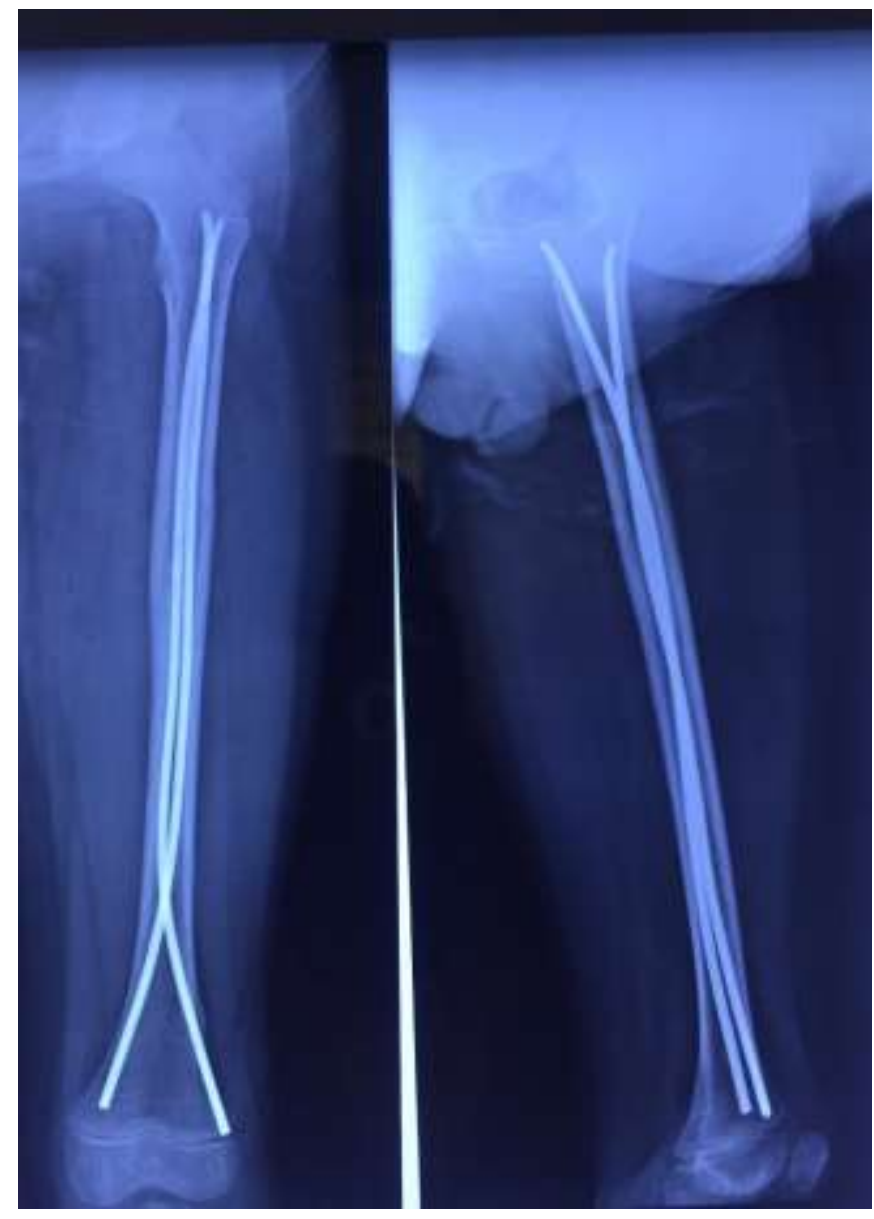

Fig 4: Four months followup xrays showing good consolidation

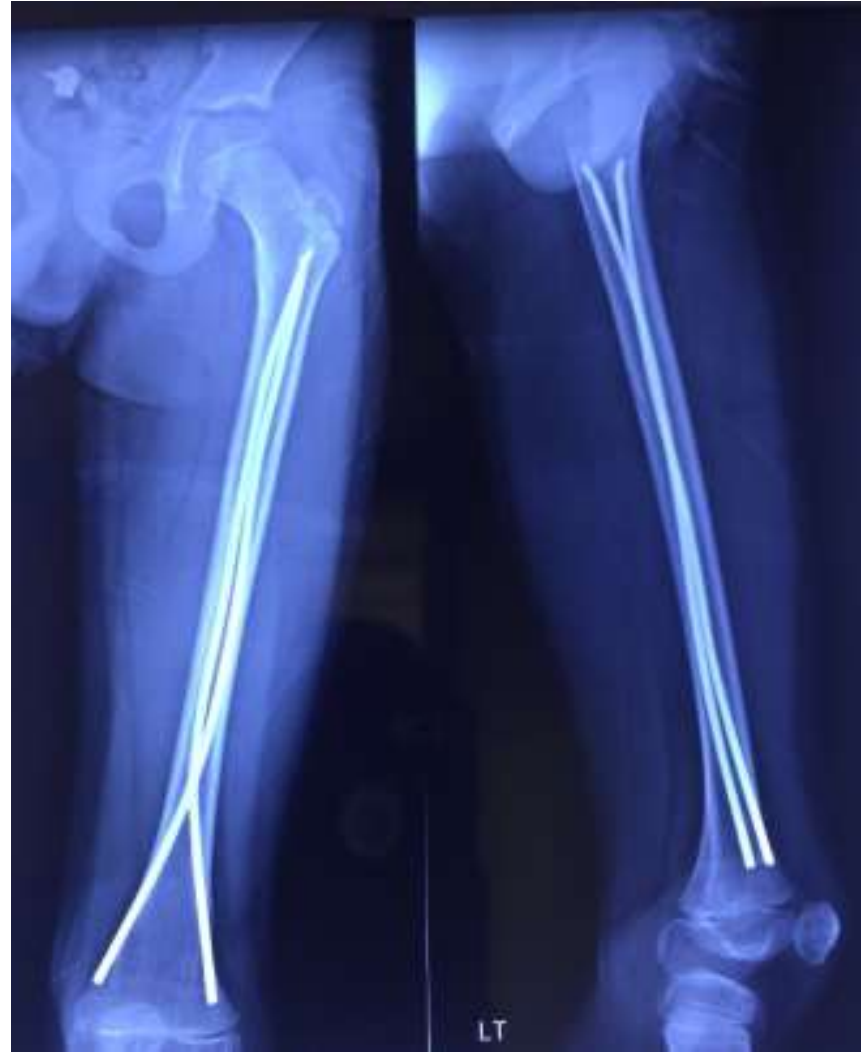

Fig 5: Follow up x-ray one year and four months duration showing good union and excellent functional results

Two cases were very comminuted and we noticed shortening of 0.5 to $1 \mathrm{~cm}$ in that cases. We have advised delayed weight bearing in that cases to avoid further collapse. There was no limb lengthening in our series. We could achieve 0 to 130 degrees of knee motion in almost $85 \%$ of cases. In three cases there was limitation of knee flexion in last 20 degrees. In that cases we found nail site inflammatory changes and also nails were cut too long. In these cases the limitation were improved only after the nail removal was done. We do not have any physeal injury, growth plate arrest, osteomyelitis in our series. Also we do not have any cases of varus and valgus angulation, rotational malalignment in our series. Uptill now we have removed nails in ten cases. we usually remove the nail after one year of the procedure. We have not found any refractures after the nail removal in our series Theoretically it is possible to remove the nail after 3 months but there are always chances of refractures with early removal of nail. Our mean follow-up was one and half years ${ }^{[4]}$.

\section{Discussion}

The diaphyseal femur fracture constitutes about $2 \%$ of the paediatric fractures. The choice of treatment remains still challenging to the orthopaedic surgeons due to high rate of complications like, malunion, joint stiffness, limb length discrepancy, late functional recovery and psychological problems in children ${ }^{[8]}$. To avoid the effects of prolonged hospitalisation, operative treatment is gaining popularity. Various operative methods are there like sub muscular plate fixation, external fixator, interlocking nails, elastic nails, Enders nails, rush nails ${ }^{[7]}$.

Plate fixation is associated with wide exposure, longer duration of immobilisation, risk of infection, large incision for plate removal. Interlocking nails are used for skeletally mature patients with risk of avascular necrosis of head, coxa valga. external fixator is associated with risk of pin tract infection, delayed weight bearing. 


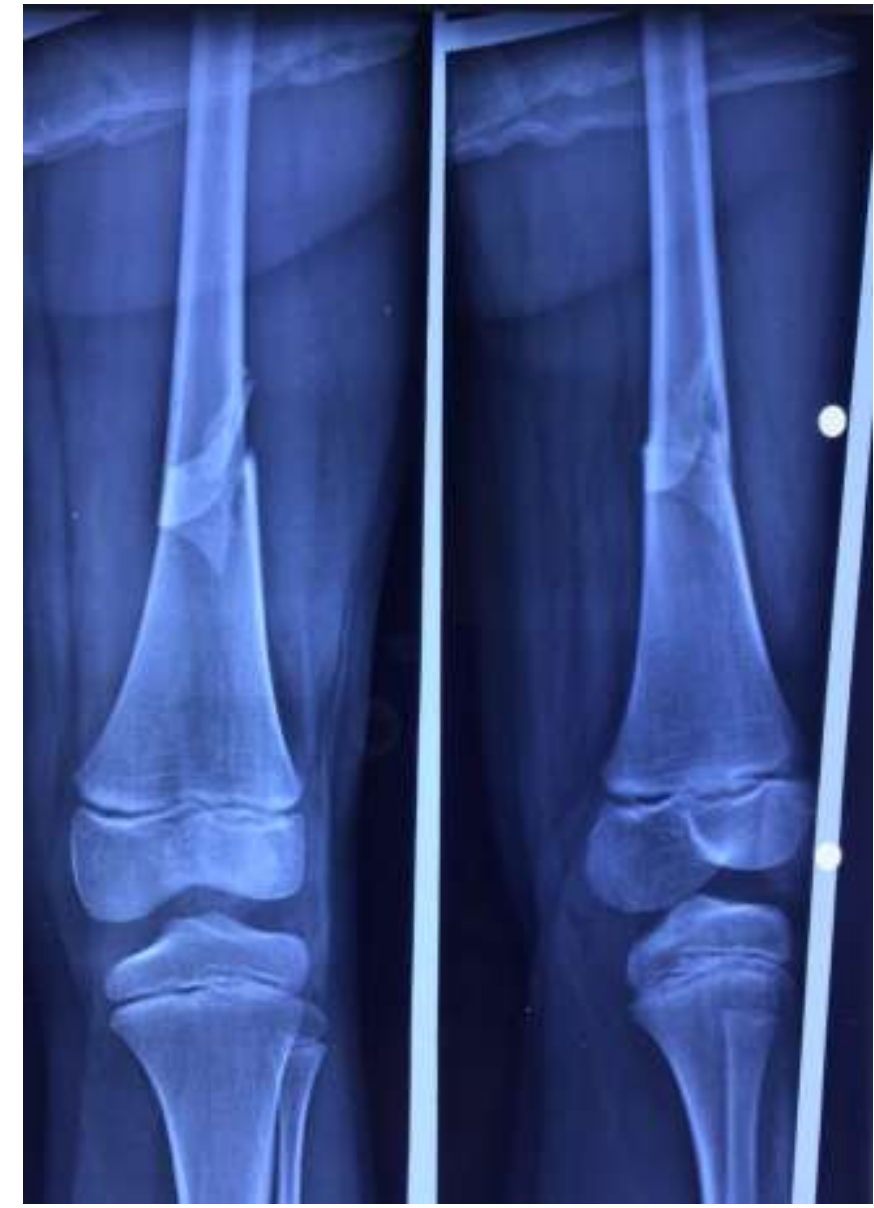

Fig 1: Preop X-ray showing Distal end Femur AP \& lat view

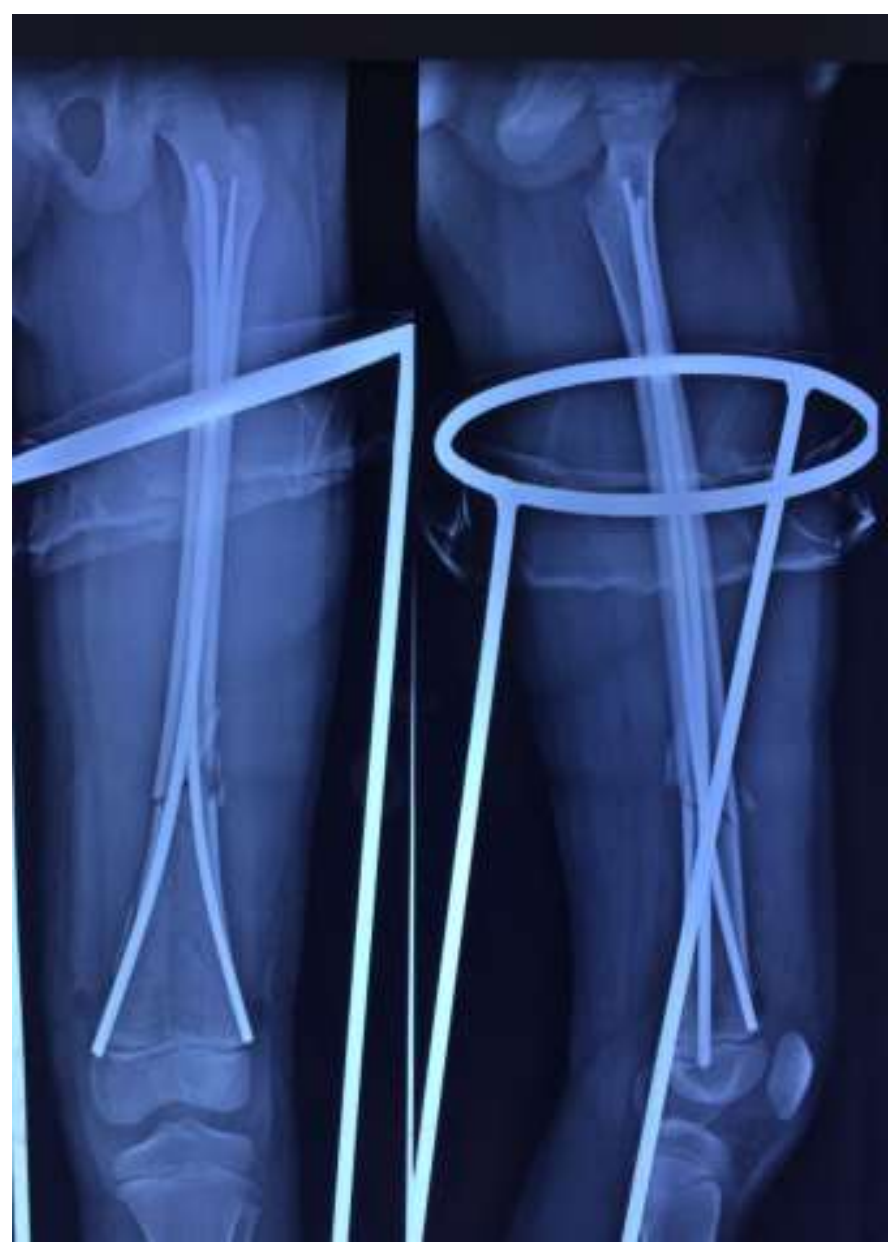

Fig 2: Immediate Post Op X-ray showing medial \& Lat ESIN in situ with post op immobilisation with Thomas spilnt

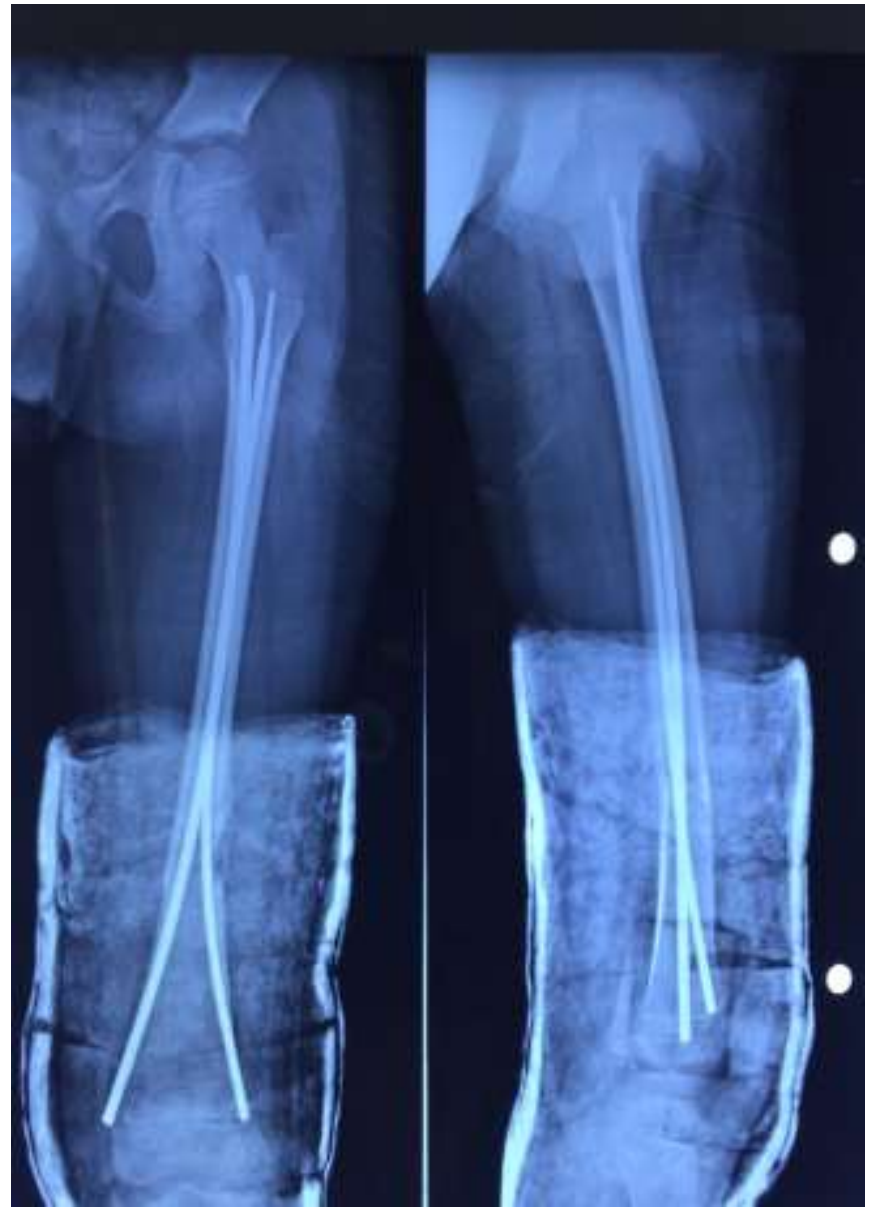

Fig 3: Two months follow - up x-ray with signs of union

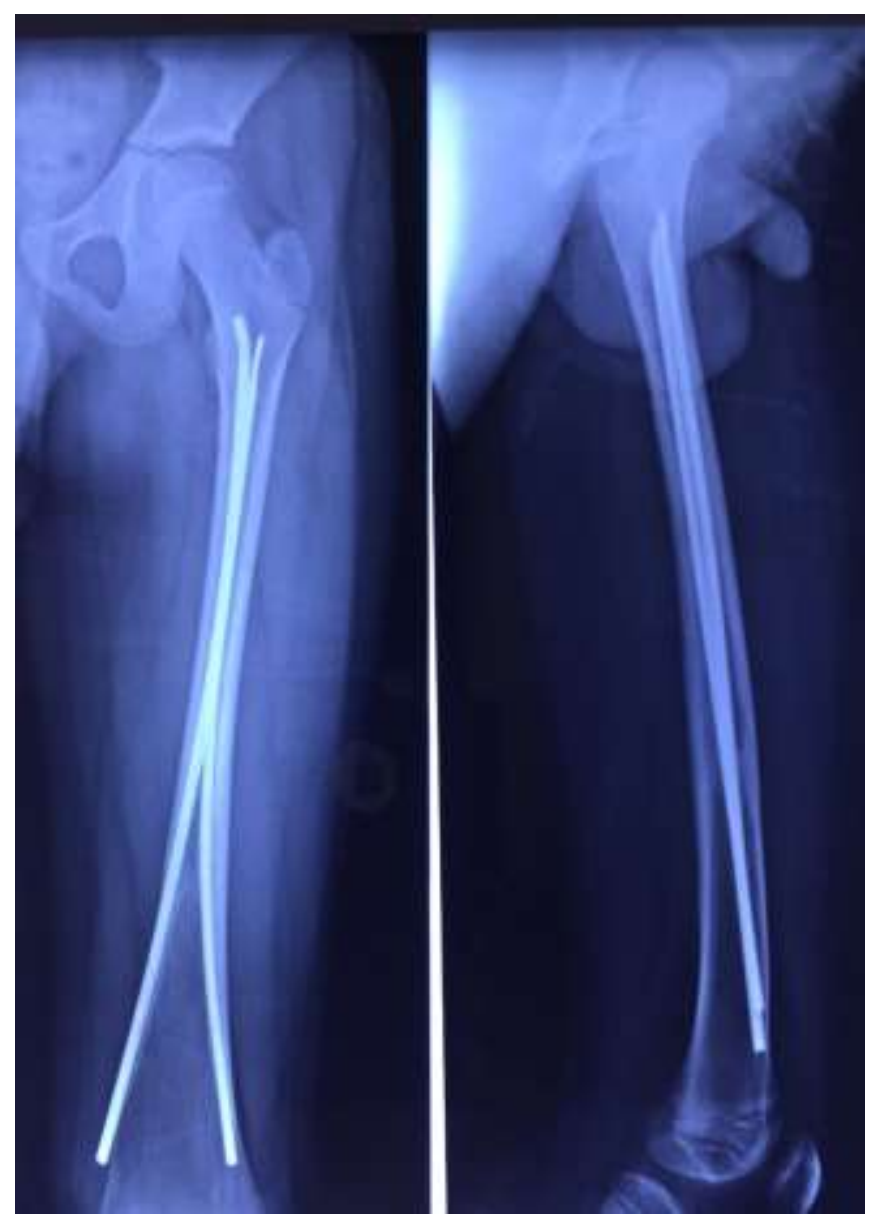

Fig 4: Two years follow up x-ray with united fracture 


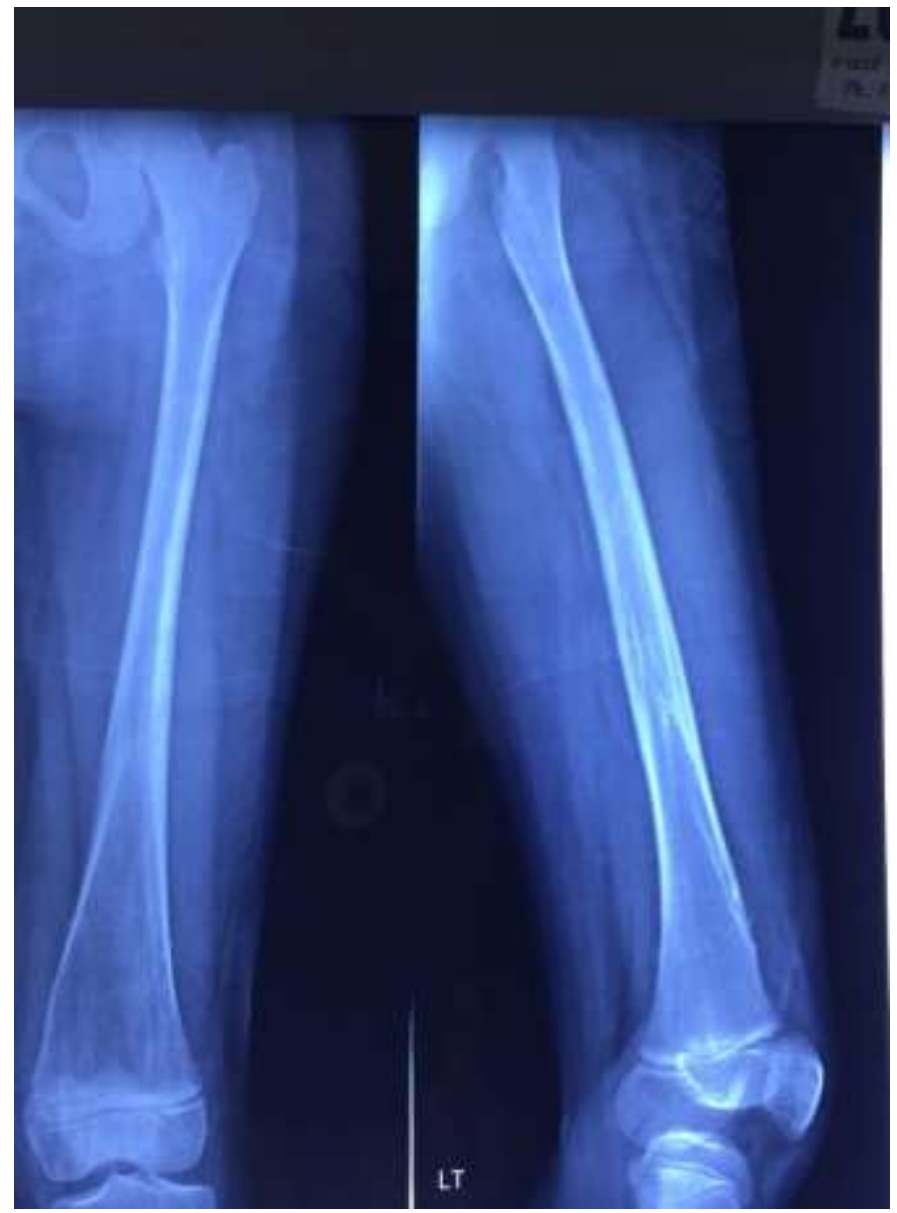

Fig 5: Xray showing good consolidation after the nail removal.

Titanium elastic nails have more advantages over the other modalities. It has got both stability and elastic mobility. The stability is mainly by the nail itself and bone \& surrounding tissues. The nail provides internal elastic support. The bone provides axial stability if there is no overlap of the fragments. This is by end to end contact of the cortices. The soft tissue plays very important role. The muscles serve as guy-ropes which help in spontaneous postoperative correction of angulation deformity ${ }^{[3]}$. ESIN allows certain amount of movement at the fracture site which encourages external callus formation by reducing shear forces and converting it into compression forces ${ }^{[9]}$. One more advantage is as its closed procedure, there is no muscle \& periosteal damage with intact fracture hematoma. As it is simple procedure, It allows early weight bearing. It is also load sharing device with internal splitage.it does not violate the epiphysis. There is no risk of infection with this technique as it is closed procedure. There is less damage to the periosteum. It also preserves fracture hematoma. Ligier et al ${ }^{[5]}$ treated 123 femoral diaphysis fractures with ESIN. All fractures united out of it only 13 patients developed entry site irritation.

Also Narayanan et al ${ }^{[6]}$ also got series of 79 cases with good outcome. Rush and Enders nail has poor rotational stability. There are some limitations with titanium elastic intramedullary nailing. It does not provide stability in severely comminuted fractures and long oblique fractures. These patients needs additional stability in the form of postoperative splint for two weeks. With the advent of recent advances in internal fixation of long bones, the results of the shaft femur fractures in children have improved a lot. But still the controversy remains with the choice of implant. But the titanium nail has considerably decreased the hospitalisation time with early return to the home. It allows biological environment which enhances fracture healing and good quality of callus formation. This technique is relatively simple, minimally invasive with normal healing. most of the complications are related with the improper technique.

\section{Conclusion}

With our series of 25 cases we feel that Titanium elastic nailing is safe effective methods of treatment of femur shaft fractures in age group of 6 to 15 years ${ }^{[9]}$. Because of the early weight bearing, rapid healing and minimal disturbance of bone growth, ESIN should be most physiological method of treatment of femur shaft fractures in age group of 6 to 14 years. This is simple technique, requires less instrumentation, easy to learn for juniors also. It has low complication rates and well accepted by the patients also.

\section{Reference}

1. Firica A, Popescu R, Scarlet M. Nov 1980. Rev Chir Orthop 1981; 67(11):82-91

2. Hunter JB. Femoral shaft fractures in children, Injury 2005; 36:s-a86-s-493

3. Houshian S, Gothgen CB, Padersen NW. Femoral shaft Fractures in children. Elastic stable intramedullary nailing in 31 cases.Acta Orthop. Scad. 2004; 75(3):24951

4. Kasser JR, Beaty KH. Femoral shaft fractures. In Rockwood and Wilkins Fractures in children, 5 Th ed. New York Ligier et al.

5. Narayanan UG, Hyman JE, Wainwright AM, Rang M, Alman BA. complications of elastic stable intramedullary nail fixation of paediatric femur fractures and how to avoid them. J pediatr Orthop. 2004; 24:363-9

6. Pankovich AM, Goldflies ML, Pearson RL. Closed ender nailing of femoral shaft fractures. J Bone Joint Sur [Am] 1979; 61-A:222-32

7. Reeves RB, Ballard RI, Huges JL. Internal fixation versus traction and casting of adolescent femoral fractures. J Pediatr Orthop.1990;10:592-5

8. Stans AA, Morrissy RT, Renwick SE. Femoral shaft fracture treatment in patient's age 6 to 16 years. J pediatr Orthop. 1999; 19(2):222-8.

9. Wright $\mathrm{Jg}-$ The treatment of femoral shaft Fractures in children: a systematic overview and clinical appraisal of the literature. Can J Surg. 2000; 43(3):180-9. 